\title{
Panama Disease: Cell Wall Reinforcement in Banana Roots in Response to Elicitors from Fusarium oxysporum f. sp. cubense Race Four
}

\author{
Ana R. D. C. F. De Ascensao and Ian A. Dubery
}

Department of Biochemistry, R.A.U. University, P.O. Box 524, Auckland Park 2006, South Africa. Accepted for publication 13 July 2000.

\section{ABSTRACT}

De Ascensao, A. R. D. C. F., and Dubery, I. A. 2000. Panama disease: Cell wall reinforcement in banana roots in response to elicitors from Fusarium oxysporum f. sp. cubense race four. Phytopathology 90:1173-1180.

The biochemical basis of tolerance in banana to Fusarium wilt, caused by the pathogen Fusarium oxysporum f. sp. cubense race four, was investigated. Tissue culture banana plants from tolerant cv. Goldfinger and susceptible cv. Williams were maintained in a hydroponic system and inoculated with conidial suspensions to evaluate the degree of tolerance to susceptibility between the two clones and to investigate the effectiveness of this technique as a potential tool for early screening for resistance in breeding programs. Similarly, defense responses were induced by treatment of the plants with an elicitor preparation from the mycelial cell walls of the pathogen. Differences in the induction of lignin and callose deposition, phenolics, and the enzymes involved in cell wall strengthening; phenylalanine ammonia lyase, cinnamyl alcohol dehydrogenase, peroxidase, and polyphenol oxidase were determined. Root tissue of the tolerant cv. Goldfinger responded to the fungal elicitor through the strong deposition of lignin, preceded by the induction or activation of the enzyme activities involved in the synthesis and polymerization thereof, whereas only slight increases were observed for the susceptible cv. Williams. No increase in callose content was observed for either clone. These results indicate an important role for cell wall strengthening due to the deposition of lignin as an inducible defense mechanism of banana roots against $F$. oxysporum f. sp. cubense race four.

Additional keyword: lignification.
Plants in nature are constantly challenged by a diverse array of pathogenic microorganisms. In many cases, their protective mechanisms involve inducible defense mechanisms. The ability of plants to invoke such defense reactions is presumed to be mediated by an initial recognition process between plants and pathogens that involves detection of certain unique signal molecules of incompatible pathogens by receptor-like molecules in plants, with a subsequent resultant cascade of biochemical events that leads to the expression of resistance $(12,21,45)$. This hypothesis is supported by the finding that compounds known as elicitors and isolated from pathogenic microorganisms induce biochemical events characteristic of the resistance responses in plants (11).

Elicitor-receptor interactions are presumed to generate signals that activate nuclear genes involved in plant defense responses leading to the induction of stress-related enzymes such as phenylalanine ammonia lyase (PAL; EC 4.3.1.5) and the associated accumulation of high levels of phenolic compounds. In addition, phenol-oxidizing enzymes such as peroxidase (POD; EC 1.11.1.7) and polyphenol oxidase (PPO; EC 1.14.18.1) are associated with many vascular diseases (39). Antimicrobial phytoalexins, synthesis of antifungal hydrolytic enzymes such as chitinases, $1,3-\beta$ glucanases, and the reinforcement of cell walls at the site of infection through increased synthesis and deposition of hydroxyproline-rich glycoproteins, callose, lignin, and phenolic compounds also contribute to multilayered plant defense systems (21).

Previous studies with Fusarium oxysporum infection of other host plants found that resistance is expressed after infection and that both the roots of resistant and susceptible plants are infected. Success or failure of resistance, therefore, depends on the rate and

Corresponding author: I. A. Dubery; E-mail address: iad@na.rau.ac.za

Publication no. P-2000-0804-01R

(C) 2000 The American Phytopathological Society extent of defense responses in the roots and vascular system of the banana host $(2,3)$.

The banana crop cultivated for commercial export is characterized worldwide by a remarkable genetic uniformity and susceptibility to Panama disease, caused by races of $F$. oxysporum f. sp. cubense. Race four has a limited distribution and is of relatively recent origin. It attacks diverse banana genomes including the AAA genotype (Cavendish and Gros Michel subgroups), and there exists a serious need to breed for increased resistance $(33,34)$. Success in breeding resistant AAAA and AAAB genotypes has been achieved, but in general, the nature of resistance of these replacements is not well characterized or unknown (40). However, banana breeding is time consuming and expensive and new genotypes produced by breeding programs have to be evaluated in field trials. Musa biological technology has progressed, and significant development of new clones may occur in the near future (37). As a first step, it is of significant importance to have an efficient screening protocol that is able to distinguish between tolerant and susceptible genotypes, because field trials have given erroneous information in the past due to nonuniform distribution of pathogens in the soil. Plant tissue culture techniques have been used for investigating mechanisms of host-pathogen relationships and have been proposed as an aid in banana breeding programs (36). In this study, Fusarium wilt susceptibility is addressed by investigating the biochemical aspects of cell wall strengthening in banana roots. The clones chosen were cv. Goldfinger, an AAAB genotype, and cv. Williams, a representative of the AAA clones (4).

\section{MATERIALS AND METHODS}

Plant material. Sterile, 4-week-old banana plantlets with known reaction to Fusarium wilt were supplied by Tropitech Technologies, Tzaneen, South Africa. The clones were cv. Williams, highly susceptible to $F$. oxysporum f. sp. cubense race four $(36,48)$ and cv. Goldfinger (FHIA-01, Honduras Foundation 
for Agricultural Research), tolerant to Fusarium wilt (44). Plantlets were removed from the sterile containers and individually transferred to 200-ml tissue culture jars containing rooting medium composed of Murashige and Skoog (MS) modified basal salts medium and supplemented with $30 \mathrm{~g} \mathrm{liter}^{-1}$ of sucrose, $0.6 \mathrm{~g} \mathrm{liter}^{-1}$ of morpholinoethanesulphonate, $2 \mathrm{~g} \mathrm{liter}^{-1}$ of gelrite ( $\mathrm{pH}$ 5.8), and a vitamin mixture consisting of $0.4 \mathrm{mg} \mathrm{liter}^{-1}$ of thiamine, $0.2 \mathrm{mg} \mathrm{liter}^{-1}$ of pyridoxine, $100 \mathrm{mg} \mathrm{liter}^{-1}$ of myoinositol, $0.4 \mathrm{mg} \mathrm{liter}{ }^{-1}$ of nicotinic acid, and $2 \mathrm{mg}^{-1}$ liter $^{-1}$ of glycine. Ascorbic acid (20 mg liter ${ }^{-1}$ ) was added as an antioxidant. The auxins and cytokinins added were 1-naphthaleneacetic acid at $10 \mu \mathrm{M}$ and benzylaminopurine at $10 \mu \mathrm{M}$, respectively. Tissue culture plantlets were kept in a growth chamber at $25^{\circ} \mathrm{C}$ on a $16-\mathrm{h}$ light 8-h dark cycle.

After 3 weeks on rooting medium, plantlets were transferred to a hydroponic system. The roots were washed with sterile-distilled water before being immersed in sterile plastic specimen jars containing $250 \mathrm{ml}$ of liquid MS basal salt mixture ( $\mathrm{pH} 5.8$ ) with no vitamins and diluted $(1: 3, \mathrm{vol} / \mathrm{vol})$ with sterile-distilled water. Plants were covered with moist polythene bags for 2 weeks to maintain similar humidity conditions as previously experienced and to prevent contamination. Sterilized air was continuously bubbled through the liquid media. Tissue culture plantlets were kept in the hydroponic system for 5 to 6 weeks with regular changes of the liquid media once a week.

Establishment of fungal cultures and elicitor preparation. A virulent strain of $F$. oxysporum $\mathrm{f}$. sp. cubense race four, isolated from roots and corms of infected banana plants from Hazyview, South Africa, was obtained from the Biotechnology division of African Explosives and Chemical Industries. The fungus was grown on potato carrot agar (PCA) before being cultivated in liquid malt extract broth at $25^{\circ} \mathrm{C}$ in darkness on an orbital shaker at $70 \mathrm{rpm}$. Heat-solubilized, nondialyzable cell wall fractions were prepared according to Ayers et al. (1). The phenolsulfuric acid method was used to quantify the elicitor fraction in terms of carbohydrate content (18). Protein was determined according to Bradford (5).

In vitro tests on susceptible and tolerant banana clones. One-week-old $F$. oxysporum f. sp. cubense race four cultures, grown on PCA medium, were used for the in vitro test. For each experiment, groups of five plantlets maintained for 6 weeks in a hydroponic system as described above, were inoculated with three concentrations of conidial suspensions $\left(2.3,4.6\right.$, and $9.2 \times 10^{4}$ conidia per $\mathrm{ml}$ ). For the control, plantlets were prepared in the same manner but grown in a conidia-free medium. Observations for wilting symptoms were carried out after 6 weeks on each plantlet. The following parameters were evaluated: plant height, number of new leaves produced, fresh weight, vascular coloration, and root necrosis. For examination of the vascular system, the pseudostem was split longitudinally into two halves. Symptom development was rated on a scale of 0 to 3 , with $0=$ no browning, $1=$ slight browning of vascular system with no external symptoms on leaves, 2 = browning of vascular system with chlorosis on leaves, and 3 = dark browning of vascular system with necrosis. The experiment was repeated three times and the results were averaged.

Elicitation and experimental design. The heat-released fraction from fungal mycelial cell walls has been widely used as elicitors (10). The effectiveness of the $F$. oxysporum f. sp. cubense elicitor was determined by investigating the induction of phenolic compounds, because phenolics play an important role in the resistance process $(2,39)$. The elicitor concentration used for the induction of the defense responses for both clones was established by treating the plants with concentrations ranging from 0 to $90 \mu \mathrm{g} \mathrm{ml}^{-1}$ and analyzing the total soluble phenolic content. The induction of soluble phenolics was clearly evident in banana clones treated with $30 \mu \mathrm{g} \mathrm{ml}^{-1}$ of elicitor, increasing up to $90 \mu \mathrm{g} \mathrm{ml}^{-1}$. All further elicitation studies were conducted with a concentration of $45 \mu \mathrm{g} \mathrm{ml}^{-1}$.

After 6 weeks in the hydroponic system, roots from well-established tissue-cultured plantlets were trimmed $1 \mathrm{~cm}$ from the root tip to expose the vascular system before being immersed in the sterile elicitor solution in diluted (1:3, vol/vol) MS basal salt medium. The roots of control plants were identically treated and immersed in diluted liquid MS basal salt solution. Following incubation for times ranging from $0,4,8,12,16,24$, and $36 \mathrm{~h}$, two to three roots were cut $2 \mathrm{~cm}$ from the original basal cut for each plant. Root segments from 10 to 12 plants per time point were pooled, frozen in liquid $\mathrm{N}_{2}$, and stored at $-20^{\circ} \mathrm{C}$ until assayed. The experiments were repeated three times under the same conditions with different sets of plants, and all analyses were performed in triplicate $(n=9)$. Results of the quantitative responses over time were analyzed using the SSPS statistical package (SPSS, Chicago) and the data fitted to a cubic equation: mean $=a_{0}+a_{1}$ time + $a_{2}$ time $^{2}+a_{3} \cdot$ time $^{3}$. Graphs of the metabolite and enzyme levels in tissue samples taken at the specified times postelicitation show the data as percent increase time $x_{x}=\left[\left\{\right.\right.$ mean $\left._{\left(\text {time }_{x}\right)}\right)-$ mean $\left(\right.$ time $\left.\left._{0}\right)\right\} /$ mean $\left(\right.$ time $\left.\left._{0}\right)\right] \times 100$. Regression coefficients are indicated in the figure legends.

Phenolic acid analysis. Pooled root segments from 10 to 12 plants per timepoint were homogenized and extracted with $(80 \%$, $\mathrm{vol} / \mathrm{vol}$ ) aqueous methanol $(9,49)$. Following reextraction of the precipitates, the supernatants were combined and divided into four microcentrifuge tubes to determine total soluble, free, methanol soluble, and ester-bound (released after alkaline hydrolysis) and methanol soluble and glycoside-bound (released after acid hydrolysis) phenolic acids. The remaining pellet was dried at $70^{\circ} \mathrm{C}$ for $24 \mathrm{~h}$. The resulting alcohol insoluble residue (AIR) yielded the cell wall material (CWM) used to extract the ester-bound cell wall phenolic acids after alkaline hydrolysis. The concentration of the phenolic acids in the extract was determined with Folin-Ciocalteau reagent and was expressed as micrograms of ferulic acid per gram fresh weight (6). Extracts from the times were analyzed in triplicate.

Lignification studies. Lignin was extracted according to the method of Bruce and West (7) and was assayed quantitatively in the AIR as thioglycolic acid derivatives following alkali hydrolysis (8). Results were expressed as the increase in $A_{280} \mathrm{~nm}$ per $5 \mathrm{mg}$ of AIR. Lignin content was also assayed by digestion of AIR root material with $25 \%$ acetyl bromide in acetic acid (46).

Determination of callose. Following homogenization in $1.5 \mathrm{ml}$ of ethanol $(80 \%, \mathrm{vol} / \mathrm{vol})$ to completely decolorize the root material, the $12,000-\mathrm{g}$ precipitates were treated with $1.5 \mathrm{ml}$ of $1 \mathrm{M}$ $\mathrm{NaOH}$ at $80^{\circ} \mathrm{C}$ for $15 \mathrm{~min}$ to solubilize callose. The supernatants were assayed for callose according to the method of Khan and Baidyanathan (23), using fluorescence with excitation at $398 \mathrm{~nm}$ and emission at $495 \mathrm{~nm}$. Callose content was expressed as pachyman equivalents per gram fresh weight.

Extraction of enzymes and assays of enzyme activity. Root segments were homogenized $(1: 2, \mathrm{wt} / \mathrm{vol})$ in the appropriate icecold extraction buffer: PPO and POD, $0.1 \mathrm{M}$ potassium phosphate buffer (pH 6.8) containing $1 \%$ Triton X-100 and $0.15 \mathrm{~g}$ of Polyclar AT (insoluble polyvinylpolypyrrolidone, Sigma Chemical Co., St. Louis); PAL, 0.2 M borate buffer (pH 8.8) containing $1 \mathrm{mM}$ EDTA, $1 \mathrm{mM}$ dithiothreitol, and Polyclar AT (5\%, wt/vol); and cinnamyl alcohol dehydrogenase (CAD), $0.1 \mathrm{M}$ Tris- $\mathrm{HCl}(\mathrm{pH}$ 7.5) containing $15 \mathrm{mM} \beta$-mercaptoethanol, ethylene glycol (10\%, $\mathrm{vol} / \mathrm{vol}$ ), and $5 \%$ Polyclar AT. The supernatants were used directly in the enzyme assays.

Protein extracts for the determination of cell wall-bound POD activity were carried out at $4^{\circ} \mathrm{C}$ (38). To isolate the ionically bound POD, the cell wall fraction was incubated with $1 \mathrm{M} \mathrm{KCl}$ for $24 \mathrm{~h}$ at $4^{\circ} \mathrm{C}$. After centrifugation, the supernatant was dialyzed for $1 \mathrm{~h}$ against distilled water and assayed for cell wall-bound POD activity.

POD activity was determined by the increase in absorbance at $470 \mathrm{~nm}$ (25). One unit of POD activity was defined as the amount capable of oxidizing $1 \mu \mathrm{M}$ guaiacol $\min ^{-1}$ to tetraguaiacol $(\varepsilon=$ $26,600 \mathrm{M}^{-1} \mathrm{~cm}^{-1}$ ) at $25^{\circ} \mathrm{C}$. PPO activity was determined using catechol as substrate and monitoring the increase in absorbance at 
$405 \mathrm{~nm}\left(\varepsilon=1,280 \mathrm{M}^{-1} \mathrm{~cm}^{-1}\right.$ [15]). PAL was assayed spectrophotometrically (22) by measuring the production of trans-cinnamic acid from L-phenylalanine at $290 \mathrm{~nm}$ in toluene $\left(\varepsilon=20,000 \mathrm{M}^{-1} \mathrm{~cm}^{-1}\right)$. CAD activity (EC 1.1.1.195) was measured following the oxidation of the appropriate hydroxycinnamyl alcohol at $30^{\circ} \mathrm{C}$ (50). Assays with coniferyl alcohol as the substrate were monitored by following the formation of coniferaldehyde at $400 \mathrm{~nm}$ $\left(\varepsilon=2.10 \times 10^{4} \mathrm{M}^{-1} \mathrm{~cm}^{-1}\right)$. Assays with sinapyl and cinnamyl alcohols were monitored at $340 \mathrm{~nm}$ following the formation of NADPH $\left(\varepsilon=6.22 \times 10^{3} \mathrm{M}^{-1} \mathrm{~cm}^{-1}\right)$. Protein content in the enzyme extracts was determined by the method of Bradford (5) with bovine serum albumin as a standard.

Electrophoretic analysis and enzyme staining procedures. The POD and PPO isoenzyme profiles from control and elicitortreated plantlets were examined by native polyacrylamide gel electrophoresis (PAGE). Slab gels, 0.75-mm-thick with $10 \%$ resolving gel and a $4 \%$ stacking gel, were prepared for anodic (24) and cathodic PAGE (14). POD isoforms were analyzed by native isoelectric focusing (43). For anodic and cathodic PAGE analysis, $15 \mu \mathrm{g}$ of soluble protein extract was loaded per well. For isoelectric focusing (IEF) analysis, $45 \mu \mathrm{g}$ of protein extract was loaded per well. POD activity was detected in the gel by 4-chloro-1naphthol (27). PPO activity was localized in the gel by immersing the gel in freshly prepared $10 \mathrm{mM}$ catechol in $0.2 \mathrm{M}$ sodium phosphate buffer $(\mathrm{pH}$ 6.8) and $o$-phenylenediamine $(0.05 \%$, wt/vol) until the PPO bands became clearly visible.

\section{RESULTS}

In vitro test on susceptible and tolerant banana clones. Tissue culture banana plantlets susceptible and tolerant to $F$. oxysporum f. sp. cubense race four were grown in vitro and were inoculated with a conidial suspension to evaluate the degree of tolerance to susceptibility between the two clones, the degree of virulence of the pathogen, and the effectiveness of this technique as a potential tool for early screening for Fusarium resistance in breeding programs. Wilting symptoms, including yellowing of leaves, on tissue culture plants inoculated with increasing concentrations of the conidial suspension began to appear on susceptible cv. Williams at 3 to 4 weeks after treatment. After 6 weeks the vascular browning in cv. Williams increased from slight browning to moderate browning to severe dark browning with necrosis as conidial inoculation was increased from 2.3 to 4.6 and $9.2 \times 10^{4}$ conidia $\mathrm{ml}^{-1}$. Root coloration and necrosis displayed a similar escalation with increasing pathogen concentration. No wilting symptoms or root necrosis were observed for cv. Goldfinger inoculated with the highest concentration of conidia, however, slight browning of the vascular system occurred. A prominent reduction in root growth was also observed for cv. Williams compared with cv. Goldfinger.

Elicitation of PAL activity. PAL activity increased four-fold over time in response to elicitor treatment for cv. Goldfinger. PAL activity increased prominently by $12 \mathrm{~h}$ postelicitation, reaching a level three-fold greater than the corresponding controls. The rise in PAL activity was transient and decreased by $24 \mathrm{~h}$ postelicitation (Fig. 1). PAL activity for cv. Williams roots increased marginally by $24 \mathrm{~h}$ postelicitation, reaching a level 1.6-fold higher than the corresponding controls.

Elicitation of phenolic acid synthesis. Changes in total soluble phenolic acids, free phenolic acids, ester-bound phenolic acids, phenolic glycosides, and phenolic acids esterified to the cell wall were quantitatively determined after treatment with $F$. oxysporum f. sp. cubense race four elicitor. Elicitation of tissue culture cv. Goldfinger roots lead to a prominent increase in total soluble phenolic acids, but a relatively small increase in free phenolic acids and a moderate increase in glycoside-bound phenolic acids was observed, compared to the corresponding controls. However, elevated levels of ester-bound phenolic acids as well as a very prominent increase in cell wall-bound phenolic acids, compared to the corresponding controls were observed, (Fig. 2A). Increased phenolics in cv. Goldfinger roots were detectable at $8 \mathrm{~h}$ and reached maximal rates of synthesis between 8 and $16 \mathrm{~h}$, whereas in cv. Williams these phenomena occurred at $12 \mathrm{~h}$ and 12 to $36 \mathrm{~h}$, respectively. Elicitation of cv. Williams roots, did not have such a prominent effect on the accumulation of phenolic acids, as that observed for cv. Goldfinger (Fig. 2B). There was a relatively small increase in total soluble, free, and glycoside-bound phenolic acids compared with the corresponding controls. Similarly, cv. Williams roots did not show such a strong increase in ester-bound and cell wall-bound phenolic acids as that observed for cv. Goldfinger.

Elicitation of POD activity and electrophoretic analysis of POD isozymes. POD activity for cv. Goldfinger increased drastically with a four-fold increase over time after inoculation with elicitor; the induced activity started to increase linearly beginning $4 \mathrm{~h}$ after inoculation and reached a maximal 3.4-fold induction above the controls after $16 \mathrm{~h}$ (Fig. 3). During the same time period, $\mathrm{cv}$. Williams roots showed no marked differences in POD activity over time after inoculation with elicitor. POD activity in cv. Williams roots increased slightly beginning $8 \mathrm{~h}$ after inoculation and reached a maximal 1.3-fold induction after 16 to $24 \mathrm{~h}$.

Separation of soluble POD isoforms were carried out on native anodic, cathodic PAGE and IEF, followed by staining with 4-chloro1-naphthol. The anionic POD isozyme patterns in response to elicitor treatment are shown in Figure 4A and 4B. These activities can be divided into two groups according to their electrophoretic mobilities. The first group of anionic isozymes ran near the cathode end of the gel. They were transiently induced and no significant increase in the number of isozymes was found for both cvs. Goldfinger and Williams. The intensity of the bands, however, increased linearly over time up to 12 to $16 \mathrm{~h}$ after elicitation. The lower group of anionic PODs (group 2), were more prominently induced by elicitor treatment for cv. Goldfinger than for $\mathrm{cv}$. Williams. At least three bands in this group were observable.

Elicitor treatment induced the middle band, which was not detected at 0 and $4 \mathrm{~h}$ after treatment but only appeared at $8 \mathrm{~h}$. The

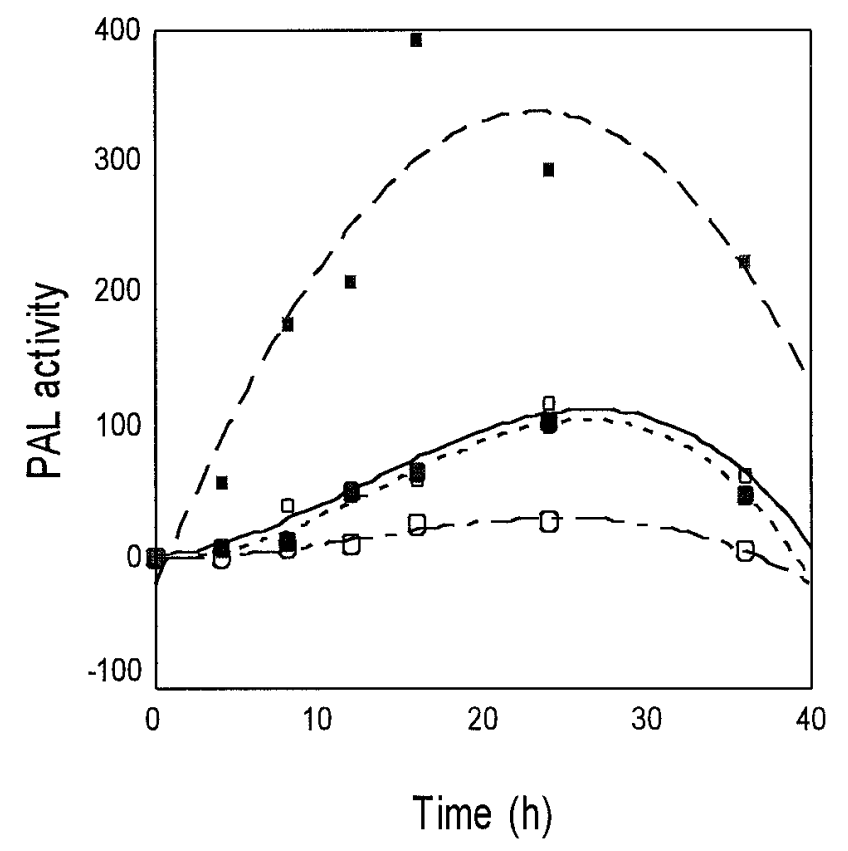

Fig. 1. Elicitation of phenylalanine ammonialyase (PAL) activity in cv. Goldfinger $(\square, \bullet)$ and cv. Williams $(\square, \bigcirc)$, roots in response to Fusarium oxysporum elicitors. Protein extracts from roots treated with elicitor $(\boldsymbol{\square}, \square)$ and control roots $(\bullet, \bigcirc)$ were assayed for PAL activity expressed as picokatals per milligram protein. The percent increase in activity compared with levels determined at $0 \mathrm{~h}$ is shown (regression coefficients: $\boldsymbol{\square}, r^{2}=0.87 ; \bullet, r^{2}=0.96$; $\square$, $\left.r^{2}=0.98 ; O, r^{2}=0.94\right)$. 
intensity of that band increased, reaching maximal induction after 12 to $16 \mathrm{~h}$ postelicitation. In the case of $\mathrm{cv}$. Williams, the group two PODs could be detected at $8 \mathrm{~h}$ and were clearly stained by $16 \mathrm{~h}$ postelicitation, however, the increased isozyme pattern was less prominent compared with that of cv. Goldfinger.

Cationic POD isozymes were resolved on native cathodic PAGE gels (data not shown). An increase in the number of in-
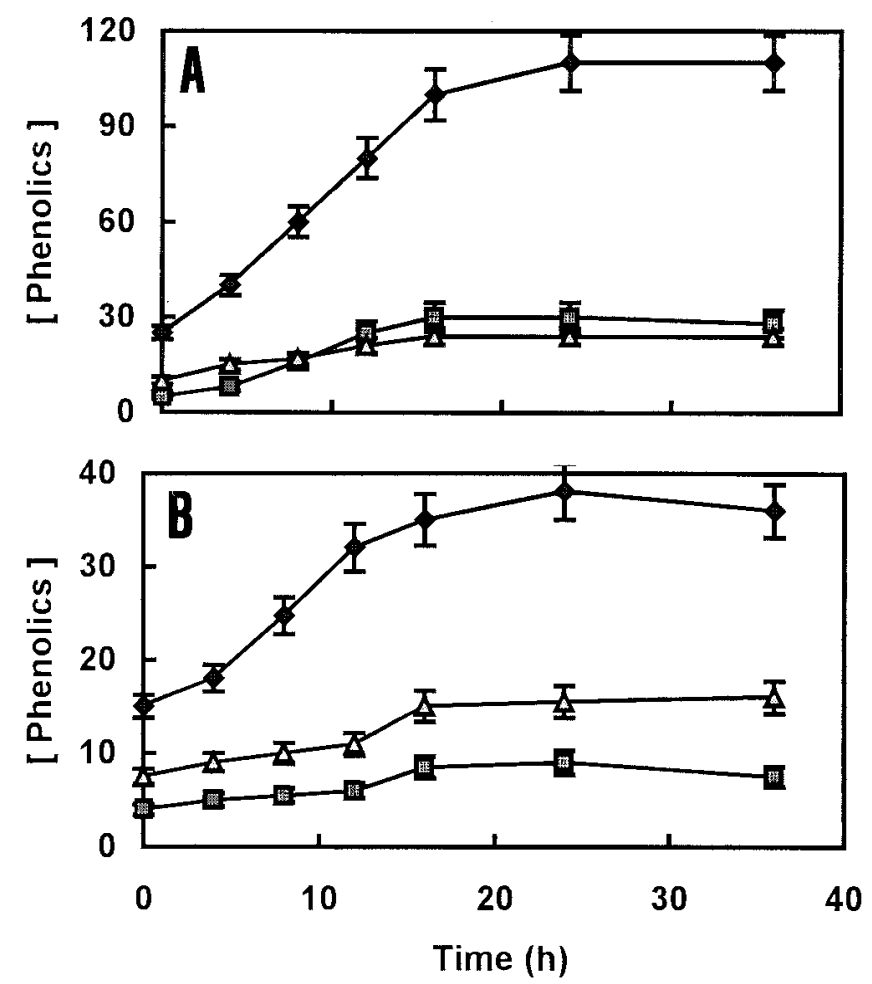

Fig. 2. The accumulation of total soluble $(\bullet)$ glycoside-bound and $(\Delta)$ ester and cell wall-bound (ם) phenolics in A, cv. Goldfinger and B, cv. Williams following elicitation. Phenolics were determined with the Folin reagent as micrograms of ferulic acid per gram fresh weight.

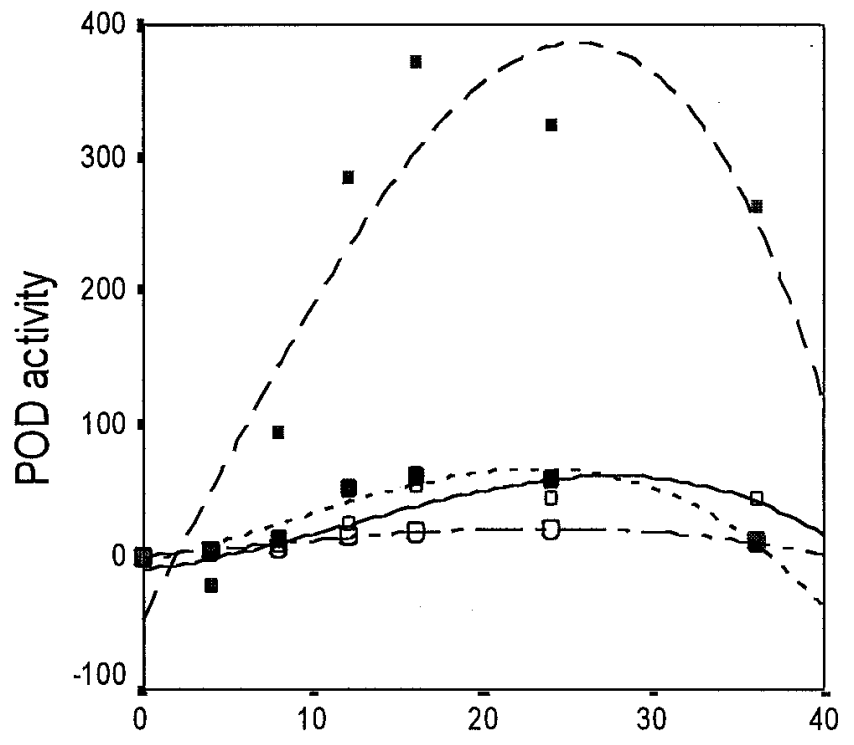

Time (h)

Fig. 3. The effect of elicitation on peroxidase (POD) activity in roots. Soluble protein extracts from roots treated with elicitor $(\boldsymbol{\square}, \square)$ and control roots $(\bullet, \bigcirc)$ were assayed for total soluble POD activity (nanokatals per milligram protein) in cv. Goldfinger $(\boldsymbol{\square}, \bullet)$ and $\mathrm{cv}$. Williams $(\square, \bigcirc)$. The percent increase in activity compared with levels determined at $0 \mathrm{~h}$ is shown (regression coefficients: $\mathbf{\square}, r^{2}=$ $\left.0.87 ; \bullet, r^{2}=0.80 ; \square, r^{2}=0.91 ; \bigcirc, r^{2}=0.96\right)$. duced cationic isozymes was found for cv. Goldfinger roots but no induction of newly expressed cationic isozymes was found for $\mathrm{cv}$. Williams, only the intensity of the bands increased over time.

Elicitation of cell wall-bound POD activity and electrophoretic analysis of isozymes. Cell wall-bound POD activity followed the same trend as for total POD. Activity in cv. Goldfinger roots increased linearly beginning $8 \mathrm{~h}$ after inoculation and reached three-fold induction after $16 \mathrm{~h}$ postelicitation (data not shown). The activity in cv. Williams roots increased slightly by $12 \mathrm{~h}$ postelicitation and reached a maximum level 1.5-fold higher than the corresponding controls. Cell wall-bound POD isozymes separated by IEF for cv. Goldfinger roots, treated with elicitor, ran in the basic and acidic regions of the gel. It was observed that the basic isozymes were constitutively expressed. Three elicitorinduced anionic isozymes were detected that reached maximum intensity after 12 to $16 \mathrm{~h}$ postelicitation. There was no observable induction of cell wall-bound POD isozymes in cv. Williams roots.

Elicitation of PPO activity and electrophoretic analysis of PPO isozymes. Markedly increased levels of PPO activity were found with the tolerant cv. Goldfinger. A three- to four-fold increase in activity over time after elicitor treatment was found for cv. Goldfinger roots compared to the corresponding 1.8 -fold increase in the controls. PPO activity for cv. Goldfinger roots increased sharply starting $4 \mathrm{~h}$ after inoculation, reaching maximal three-fold induction above the controls after $12 \mathrm{~h}$ (Fig. 5). The timing and extent of activation of PPO were more rapid and to a
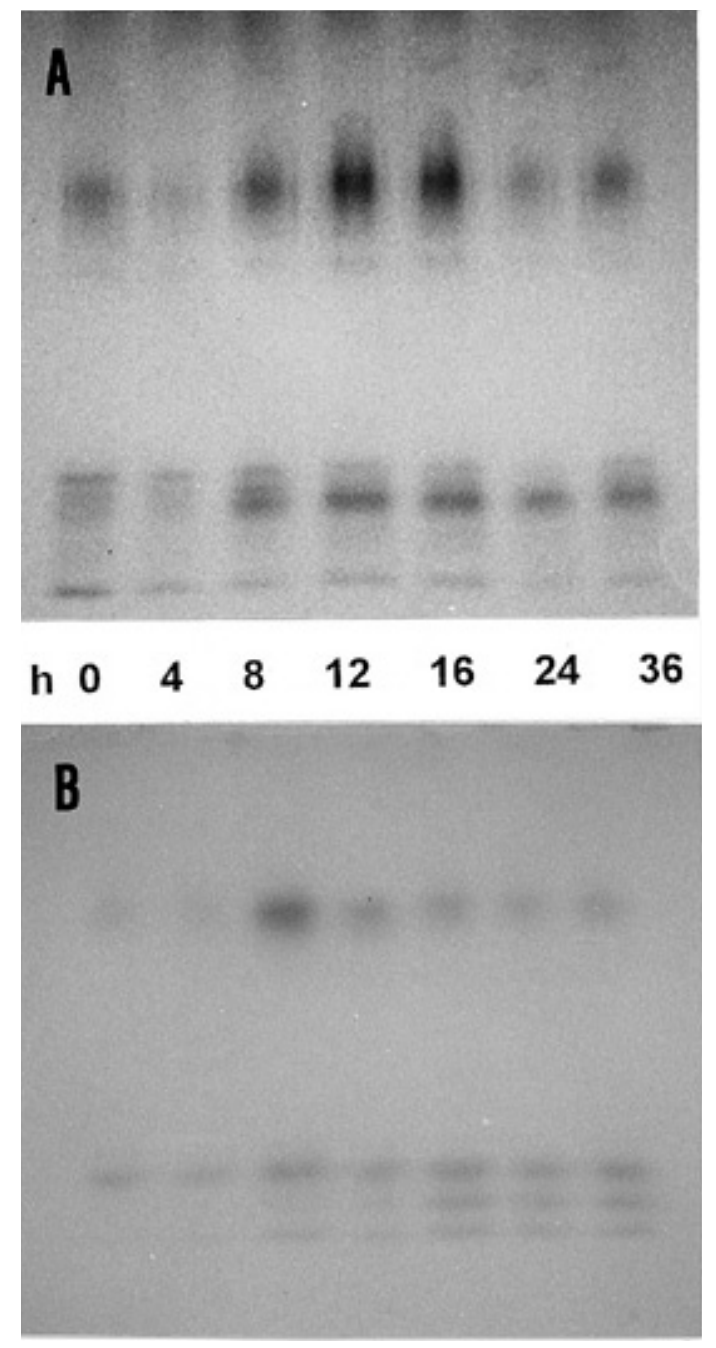

Fig. 4. Induction of peroxidase (POD) isozymes in elicited root tissue of $\mathbf{A}, \mathrm{cv}$. Goldfinger and B, cv. Williams. Extracts containing $15 \mu \mathrm{g}$ of total protein per lane were electrophoresed on native anodic polyacrylamide gel electrophoresis gels and stained for POD activity with 4-chloro-1-naphthol. 
greater extent in cv. Goldfinger roots than in cv. Williams. PPO activity for cv. Williams roots increased linearly beginning $12 \mathrm{~h}$ after inoculation and reached a maximal 1.5-fold induction after $36 \mathrm{~h}$.

The spectrophotometric determination of PPO activity correlated with the PPO isozyme pattern observed following elicitation. Separation of PPO isoforms for cvs. Goldfinger and Williams was carried out on native anodic PAGE, followed by staining with $10 \mathrm{mM}$ catechol and $o$-phenylenediamine $(0.05 \%$, wt/vol). Elicitortreatment of cv. Goldfinger greatly induced the number and intensity of PPO isoforms; with new acidic isoforms induced at $>8 \mathrm{~h}$ and the highest induction being reached after 12 to $16 \mathrm{~h}$ postelicitation (Fig. 6A). Elicitor treatment of cv. Williams induced a number of PPO isozymes, although the induction only occurred at $24 \mathrm{~h}$, reaching a maximum after $36 \mathrm{~h}$ (Fig. 6B).

Elicitation of cinnamyl alcohol dehydrogenase activity. The substrate-specificity of CAD induction was examined by comparing the assay with the following three substrates: cinnamyl, coniferyl, and sinapyl alcohol. There was no activity when cinnamyl alcohol was used as a substrate. Coniferyl alcohol dehydrogenase activity in elicitor-treated tissue culture roots increased slightly in comparison with the control levels. However, the activity of CAD with sinapyl alcohol as substrate increased sevenfold over time in elicitor-treated cv. Goldfinger roots. Increased levels of sinapyl alcohol dehydrogenase activity were observed by $12 \mathrm{~h}$ postelicitation and it continued to increase, reaching a maximum 4.2-fold induction higher than the corresponding controls (Fig. 7). This increase in CAD activity suggests that this enzyme plays an important role in lignification as a means of plant defense. In comparison, sinapyl alcohol dehydrogenase activity increased slightly (2.4-fold) in elicitor-treated cv. Williams roots but only reaching a level of 1.6-fold higher than the corresponding controls.

Elicitation of lignin formation and deposition. Accumulation of lignin-like material in cell walls of mature banana roots was assayed quantitatively by derivatization with thioglycolic acid from AIR of root CWM. The assay was compared with an independent study involving digestion of AIR root material with $25 \%$ acetyl bromide in acetic acid in order to confirm that the material that accumulated in elicited roots was indeed lignin. With both

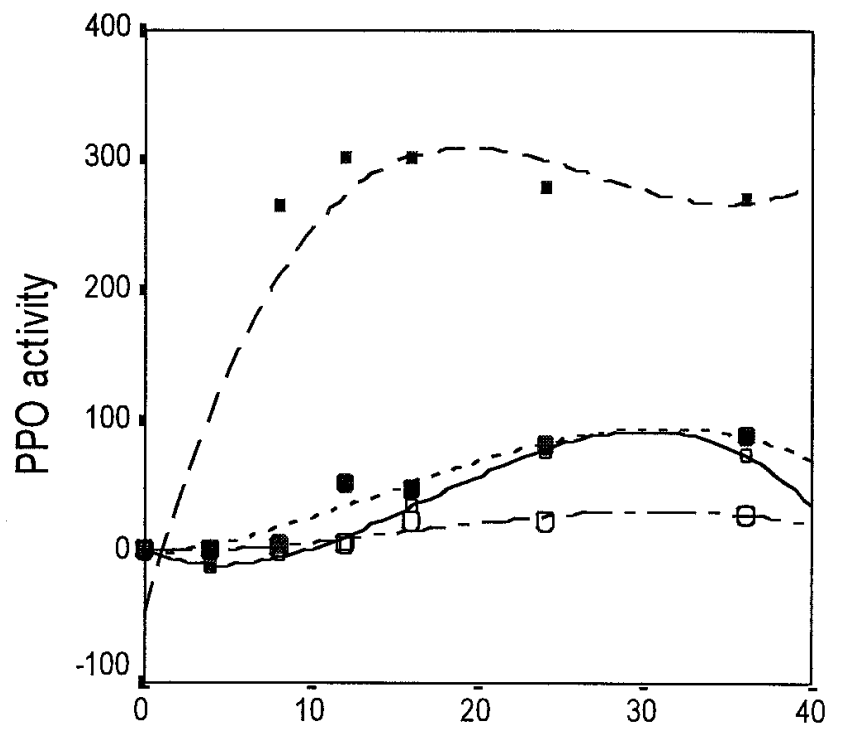

Time (h)

Fig. 5. Induction of polyphenoloxidase (PPO) activity in cv. Goldfinger $(\boldsymbol{\square}, \bullet)$ and cv. Williams $(\square, \bigcirc)$ roots. Extracts from roots treated with elicitor $(\boldsymbol{\square}, \square)$ and control roots $(\bullet, \bigcirc)$ were assayed for total soluble PPO activity expressed as nanokatals per milligram protein. The percent increase in activity compared with levels determined at $0 \mathrm{~h}$ is shown (regression coefficients: $\mathbf{\square}, r^{2}=0.83 ; \bullet, r^{2}=$ $0.99 ; \square, r^{2}=0.94 ; \bigcirc, r^{2}=0.92$ ). assays the first detectable increase in lignin for tissue culture cv. Goldfinger roots, occurred after $4 \mathrm{~h}$ following elicitor treatment. Lignin accumulated at a rapid and constant rate during the 4 to $16 \mathrm{~h}$ interval, followed by a slow increase up to $36 \mathrm{~h}$ (Fig. 8). Treatment with elicitor induced a 4.5-fold increase in lignin content for cv. Goldfinger roots, but only a 1.5 -fold increase for cv. Williams. The first detectable increase in lignin for cv. Williams roots occurred between $12 \mathrm{~h}$ and $16 \mathrm{~h}$, and accumulated slightly up to $36 \mathrm{~h}$.

Elicitation of callose. The fluorometric determination of callose content in tissue culture cv. Goldfinger roots showed no significant accumulation of callose in response to elicitor. Callose content increased 2.6-fold over time in elicitor-treated cv. Goldfinger roots compared with the 2.2-fold increase observed in elicitor-treated cv. Williams roots. Callose formation in cv. Goldfinger roots started $16 \mathrm{~h}$ postelicitation and increased transiently up to $36 \mathrm{~h}$ (data not shown). This increase in callose content was low, with a 1.4-fold induction observed compared with the corresponding controls for cv. Goldfinger and a 1.3-fold increase for cv. Williams.

\section{DISCUSSION}

It was evident from studies in the early 1920s that invasion of the vascular system of banana by $F$. oxysporum f. sp. cubense required rupture of the vascular elements. Our comparative studies on induced defense responses between cvs. Goldfinger and
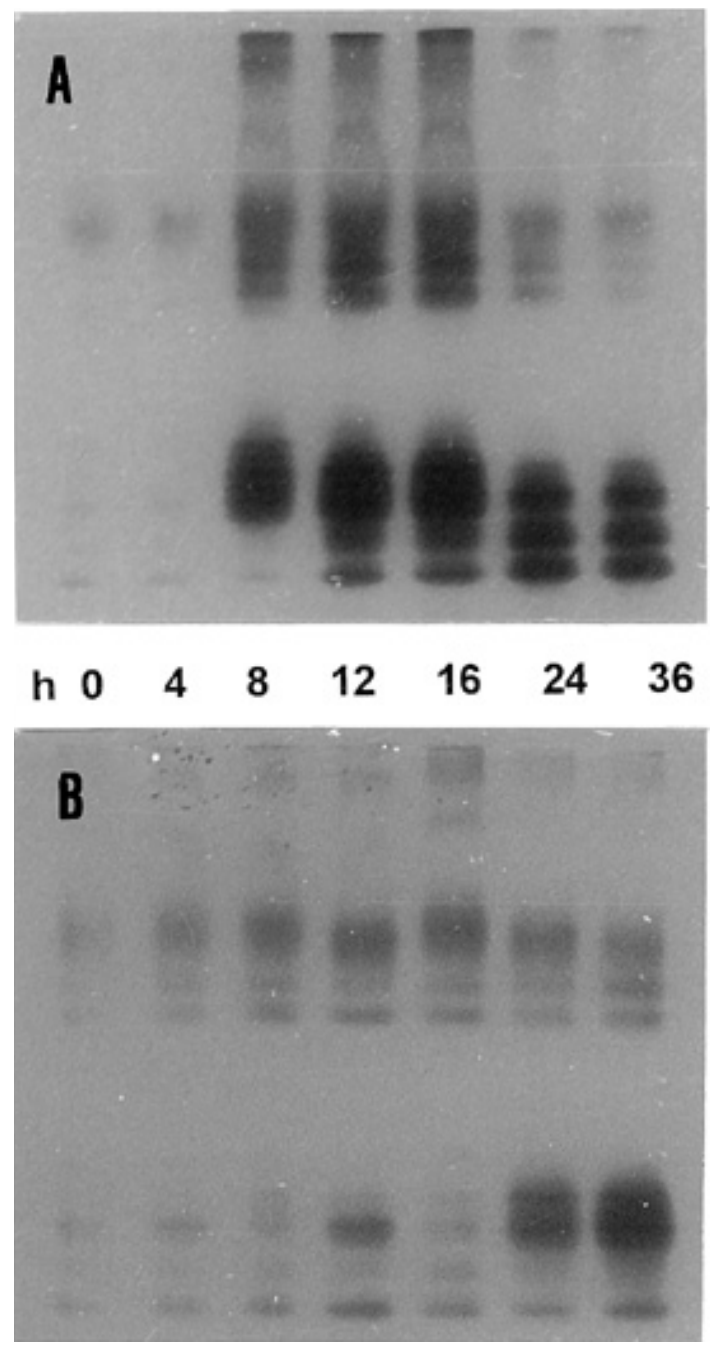

Fig. 6. Induction of polyphenoloxidase (PPO) isozymes in elicited root tissue of A, cv. Goldfinger and B, cv. Williams. Extracts containing $15 \mu \mathrm{g}$ of total protein per lane were electrophoresed on native anodic polyacrylamide gel electrophoresis gels and stained for PPO activity with $10 \mathrm{mM}$ catechol and $0.05 \% \mathrm{o}$ phenylenediamine. 
Williams utilized the inoculation of trimmed roots, with either a conidial suspension or a solution of cell wall-derived elicitor to simulate the rupture of the vascular elements required for the invasion of the vascular system by $F$. oxysporum f. sp. cubense; often followed by or associated with nematode infection. Live pathogen was not used due to the high level of variability in the induced responses.

Our results indicate that this in vitro conidia technique could be used for early screening for $F$. oxysporum f. sp. cubense resistance, but much remains to be learned about biochemical factors that influence disease development in plantlets. To investigate the biochemical responses, the plant-pathogen interaction was simplified through the use of cell wall-derived elicitors that elicit a quantitatively similar responses of the live pathogen $(11,12)$.

PAL activity is an extremely sensitive indicator of stress conditions and fungal challenge, and elicitor treatment elevates the levels of the flux through the general phenylpropanoid pathway, thereby supplying the carbon skeletons for secondary products such as phenolics which are the precursor molecules for lignin. The observed increase in PAL activity in elicited roots is presumably related to the lignification process. This is supported by the observations that accumulation of lignin correlates with elevated levels in PAL activity for tolerant cv. Goldfinger plants. Similarly, a small increase in PAL activity of elicitor-treated cv. Williams roots correlated with the relatively small increase in lignin content.

Defense responses are characterized by the early accumulation of phenolic compounds at the infection site that slow development of the pathogen occurring as a result of rapid cell death $(13,30)$. Synthesis of cell wall-bound esters may commence immediately on exposure to fungal challenge. The esterification with hydroxycinnamic acids modifies the cell wall polysaccharides to resist the action of lytic enzymes produced by fungal pathogens. These esters may become cross-linked and provide a platform for later lignification (29). In the tolerant clone, cell wall-bound-esterified phenolics were the largest subfraction of the total phenolics in contrast to the susceptible clone where glycoside-bound phenolics occurred in approximately equal concentrations.

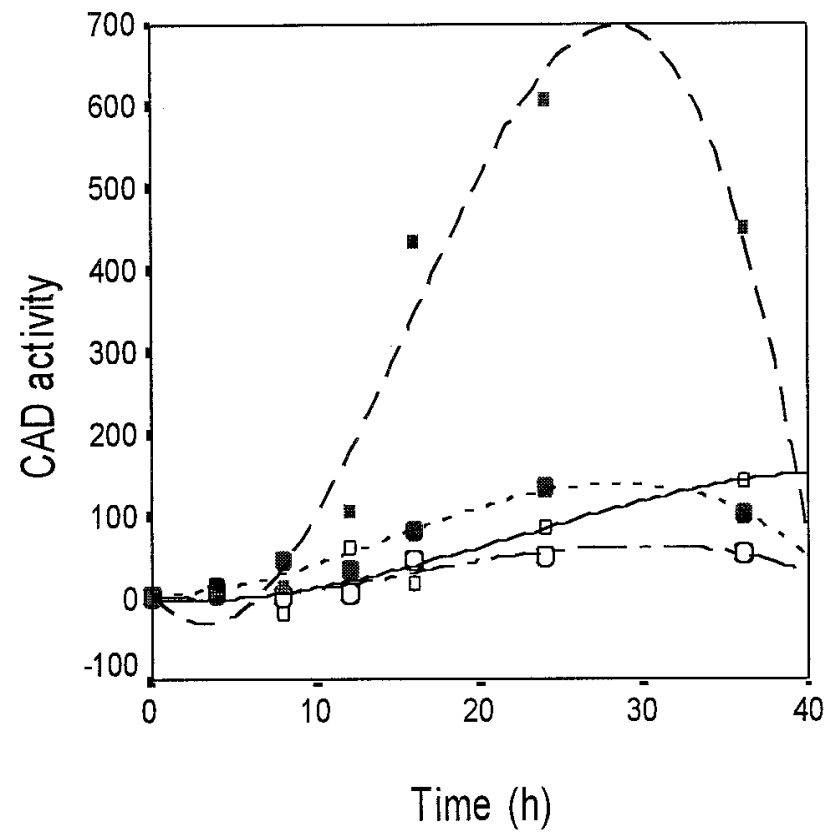

Fig. 7. Elicitation of cinnamyl alcohol dehydrogenase activity in cv. Goldfinger $(\square, \bullet)$ and cv. Williams $(\square, \bigcirc)$ roots in response to Fusarium oxysporum elicitors. Extracts from roots treated with elicitor $(\boldsymbol{\square}, \square)$ and control roots $(\bullet, \bigcirc)$ were assayed for CAD activity (picokatals per milligram protein) with sinapyl alcohol as substrate. The percent increase in activity compared with levels determined at $0 \mathrm{~h}$ is shown (regression coefficients: $\mathbf{\square}, r^{2}=0.96 ; \bullet, r^{2}=0.86 ; \square, r^{2}=0.95 ; \bigcirc, r^{2}=$ $0.88)$.
Although PAL, POD, and PPO play significant roles in the lignin biosynthesis pathway, these activities are relatively nonspecific markers for lignification in comparison to the lesser-studied CAD activity. This enzyme is an indicator of lignin biosynthesis because of its specific role at the end of the monolignol biosynthetic pathway $(16,32)$. This prominent increase in sinapyl alcohol dehydrogenase activity in the tolerant clone suggests that this enzyme plays an important role in the lignification response and correlates with the lignin concentration determined.

Isoforms of POD and PPO and the quantities produced vary among banana genotypes (19). Because the activity levels and number of isozymes produced are the greatest in banana roots, it is postulated that they may help protect plants against infection by root pathogens $(35,40)$. The appearance of new isozymes of POD or PPO in infected tissue may have unique functions in defense. A current model involving POD in defense mechanisms considers the condensation of phenolic monomers derived from the phenylpropanoid pathway into insoluble polymers (42), catalyzed by anionic PODs. Results obtained in this study on POD activity indicated that the tolerant plants responded actively to elicitation through the rapid induction or activation of specific isoforms. It is thought that the anionic PODs that are associated with the cell wall function during lignification (26). In the case of the susceptible clone, limited induction of these isoforms was found.

PPO activity is ubiquitous in higher plants, and functions attributed to the enzyme include phenol metabolism and a defense mechanism against pathogens $(28,31)$. Several observations have identified a role for PPO in the polymerization of monolignols into olignols, precursor molecules of lignin. The possible involvement of PPO in defense in banana roots was suggested by the markedly increased levels of PPO activity after elicitation. Results indicated that tolerant plants responded actively to elicitation through the rapid induction and differential activation of specific isoforms. Based on the differential ability of PPO and POD to drive the oxidation and condensation of lignin precursors in vitro, it has been suggested that PPO may be primarily responsible for the initial polymerization of monolignols into olignols (47), whereas POD would be more likely to catalyze the reactions leading from olignols to highly condensed macromolecular lignin.

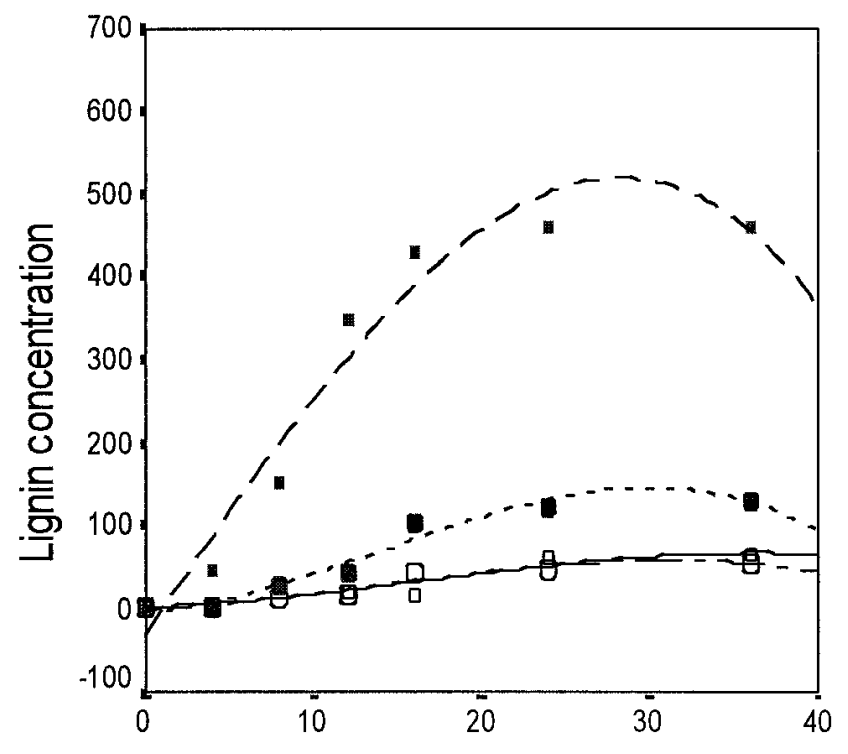

\section{Time (h)}

Fig. 8. The accumulation of lignin in cv. Goldfinger $(\boldsymbol{\square , \bullet})$ and cv. Williams $(\square, \bigcirc)$ roots measured by the thioglycolic acid assay. Elicitor-treated roots $(\boldsymbol{\square}, \square)$ and control roots $(\bullet, 0)$ were assayed at $0,4,8,12,16,24$, and 36 h postelicitation. The percent increase in lignin compared with levels determined at $0 \mathrm{~h}$ is shown (regression coefficients: $\mathbf{\square}, r^{2}=0.96 ; \bullet, r^{2}=0.88 ; \square, r^{2}=0.97 ; \bigcirc, r^{2}=0.96$ ). 
The accumulation of lignin and lignin-like material in infected plant tissues are widely reported defense phenomena. Lignin is a three-dimensional phenolic structure resulting from the free-radical polymerization of $p$-coumaryl, coniferyl, and sinapyl alcohols in the plant cell wall. Lignin is highly resistant to attack by microorganisms, and lignified cell walls are an effective barrier to pathogen entrance and spread (41). Strong, rapid lignification played a significant role in the elicited defense response of the roots of the tolerant clone.

It has been suggested that plants have flexible detection systems, probably employing several recognition and signal transduction pathways to activate their defense (20). Overall, precise temporal and spatial coordination of induced defense responses are required to successfully kill or restrict the invading microbe while simultaneously minimizing the damage to host tissue (17).

Although most individual responses are additive in their effect on resistance, it is important to note that the only reported mechanism that acts as a defense against $F$. oxysporum f. sp. cubense in banana is a prompt response to infection mediated by the build up of mechanical barriers, vascular occluding gels and tyloses that may prevent the spread of the pathogen to the vascular system $(2,3)$. Esterification with hydroxycinnamic acids modifies the cell wall polysaccharides and may become cross-linked and provide a platform for later lignification (29) to resist the action of lytic enzymes produced by fungal pathogens. Success or failure of resistance may, therefore, depend on the relative rate and extent of the host's lignification response.

The results obtained in this study are a necessary and important first step toward understanding the biochemical basis of the genetically determined resistance of banana clones toward $F$. oxysporum f. sp. cubense race four. In conclusion, compared to cv. Williams, the cv. Goldfinger has a greater capacity for phenolic metabolism with regard to the basal levels of associated enzymes and metabolites. Cv. Goldfinger responds strongly to elicitation through cell wall strengthening, the deposition of lignin, and associated timeous induction of the associated enzymes involved in the lignin pathway. This defense mechanism appears to be an important determinant affecting the outcome of the host's response to $F$. oxysporum $\mathrm{f}$. sp. cubense race four and may be a possible contributing factor to the resistance mechanism in cv. Goldfinger.

Comparison of the biochemical assays done on tissue culture plants with adult plants showed few differences, indicating that there is practical value in using tissue culture plantlets for the selection of resistance to pathogens and offering an alternative to field trials of new genotypes produced in banana breeding programs.

\section{ACKNOWLEDGMENTS}

We thank the National Research Foundation and A.E.C.I. Ltd. for financial support, Tropitech Technologies for banana plants and fungal cultures, K. J. Kunert and B. Okole for cooperation, and R. Eiselen for help with statistical analyses.

\section{LITERATURE CITED}

1. Ayers, A. R., Ebel, J., Valent, B., and Albersheim, P. 1976. Hostpathogen interactions. XI. Composition and structure of wall released elicitor fractions. Plant Physiol. 57:766-774.

2. Beckman, C. H. 1987. The Nature of Wilt Disease of Plants. The American Phytopathological Society, St. Paul, MN

3. Beckman, C. H. 1990. Host responses to the pathogen. Pages 107-114 in: Fusarium Wilt of the Banana. R. C. Ploetz, ed. The American Phytopathological Society, St. Paul, MN.

4. Bonner, J. E., Warner, R. M., and Brewbaker, J. L. 1974. A chemosystematic study of Musa clones. Hortic. Sci. 9:325-328.

5. Bradford, M. M. 1976. A rapid and sensitive method for the quantitation of microgram quantities of protein using the principle of protein-dye binding. Anal. Biochem. 72:248-259.

6. Bray, H. G., and Thorpe, W. V. 1954. Estimation of Phenols. Pages 27-55 in: Methods of Biochemical Analysis. D. Glick, ed. Interscience Publishing Inc., New York.
7. Bruce, R. J., and West, C. A. 1982. Elicitation of casbene synthetase activity in castor bean: The role of pectic fragments of the plant cell wall in elicitation by a fungal endopolygalacturonase. Plant Physiol. 69: 1181-1188.

8. Campbell, M. M., and Ellis, B. E. 1992. Fungal elicitor-mediated responses in pine cell cultures: Cell wall-bound phenolics. Phytochemistry 31:737-742.

9. Cvikrová, M., Nedelnik, J., Eder, J., and Binarová, P. 1993. Changes in pattern of phenolic acids induced by culture filtrate of Fusarium oxysporum in alfalfa plants differing in susceptibility to the pathogen. J. Plant Physiol. 142:1-5.

10. Darvill, A. G., and Albersheim, P. 1984. Phytoalexins and their elicitors: A defense against microbial infection in plants. Annu. Rev. Plant Physiol. 35:243-275.

11. Dixon, R. A., and Harrison, M. J. 1990. Activation, structure, and organization of genes involved in microbial defense in plants. Adv. Genetics 28:165-234.

12. Dixon, R. A., Harrison, M. J., and Lamb, C. J. 1994. Early events in the activation of plant defense responses. Annu. Rev. Phytopathol. 32:479-501.

13. Fernandez, M. R., and Heath, M. C. 1989. Interaction of the nonhost French bean plant (Phaseolus vulgaris) with parasitic and saprophytic fungi. III. Cytologically detectable responses. Can. J. Bot. 67:676-686.

14. Gabriel, O. 1971. Disc gel electrophoresis. Methods Enzymol. 22:565-603.

15. Gauillard, F., Richard-Forget, F., and Nicholas, J. 1993. A new spectrophotometric assay for polyphenol oxidase activity. Anal. Biochem. 215:59-65.

16. Grand, C., Sarni, F., and Boudet, A. M. 1985. Inhibition of cinnamyl alcohol dehydrogenase activity and lignin synthesis in poplar (Populus $\times$ euramericana Dode) tissues by two organic compounds. Planta 163: 232-237.

17. Hammond-Kosack, K. E., and Jones, J. D. G. 1996 Resistance genedependent plant defense responses. Plant Cell 8:1773-1791.

18. Hirs, C. H. W. 1967. Glycopeptides. Methods Enzymol. 11:411-413.

19. Jarret, R. L., and Litz, R. E. 1986. Enzyme polymorphism in Musa acuminata colla. J. Hered. 77:183-188.

20. Johal, G. S., Gray, J., and Briggs, S. P. 1995. Convergent insights into mechanisms determining disease and resistance response in plant-fungal interactions. Can. J. Bot. 73(Suppl.):468-474.

21. Keen, N. T. 1992. The molecular biology of disease resistance. Plant Mol. Biol. 19:109-122.

22. Khan, U. N., and Vaidyanathan, C. S. 1987. A new spectrophotometric assay of phenylalanine ammonia-lyase. Curr. Sci. 8:391-393.

23. Köhle, H., Jeblick, W., Poten, F., Blaschek, W., and Kauss, H. 1985. Chitosan-elicited callose synthesis in soybean cells as a $\mathrm{Ca}^{2+}$-dependent process. Plant Physiol. 77:544-551.

24. Laemmli, U. K. 1970. Cleavage of structural proteins during the assembly of the head of bacteriophage T4. Nature 227:680-685.

25. Lagrimini, L. M., Bradford, S., and Rothstein, S. 1990. Peroxidaseinduced wilting in transgenic tobacco plants. Plant Cell 2:7-18.

26. Lagrimini, L. M., Burkhart, W., Moyer, M. and Rothstein, S. 1987. Molecular cloning of complementary DNA encoding the lignin-forming peroxidase from tobacco: Molecular analysis and tissue-specific expression. Proc. Natl. Acad. Sci. USA 84:7542-7546.

27. Lagrimini, M. L., and Rothstein, S. 1987. Tissue specificity of tobacco peroxidase isozymes and their induction by wounding and tobacco mosaic virus infection. Plant Physiol. 84:438-442.

28. Lax, A. R., and Cary, J. W. 1995. Biology and molecular biology of polyphenol oxidase. Am. Chem. Soc. 9:121-128.

29. Lewis, N. G., and Yamamoto, E. 1990. Lignin: Occurrence, biogenesis, and biodegradation. Annu. Rev. Physiol. Plant Mol. Biol. 41:455-496.

30. Mace, M. E. 1963. Histochemical localization of phenols in healthy and diseased banana roots. Physiol. Plantarum. 16:915-925.

31. Mace, M. E., and Wilson, E. M. 1964. Phenol oxidases and their relation to vascular browning in Fusarium infected banana roots. Phytopathology $54: 840-842$.

32. Moerschbacher, B. M., Flott, B. E., Noll, B. E., and Reisener, H. J. 1990. On the specificity of an elicitor preparation from stem rust which induces lignification in wheat leaves. Plant Physiol. Biochem. 27:305-315.

33. Morpurgo, R., Brunner, H., Grasso, G., Van Duren, M., Roux, N., and Afza, R. 1997. Enigma of banana breeding: A challenge for biotechnology. Agro Food Ind. Hi-Tech 8:16-21.

34. Morpurgo, R., Lopato, S. V., Afza, R., and Novak, F. J. 1994. Selection parameters for resistance to Fusarium oxysporum f. sp. cubense race 1 and race four on diploid banana (Musa acuminata Colla). Euphytica 75:121-129.

35. Mueller, W. C., and Beckman, C. H. 1978. Ultrastructure localization of polyphenol oxidase and peroxidase in roots and hypocotyls of cotton seedlings. Can. J. Bot. 56:1579-1587.

36. Novak, F. J. 1992. Musa (bananas and plantains). Pages 449-488 in: Biotechnology of Perennial Fruit Crops. F. A. Hammerschlag and R. E. Litz, 
eds. Commonw. Agric. Bur. Int. Walingford, Oxon, U.K.

37. Novak, F. J., Brunner, H., Afza, R., Morpurgo, R., Upadhay, R. K., Van Duren, M., Sacchi, M., and Kaemmer, D. 1992. Improvement of Musa through biotechnology and mutation breeding. Pages 143-158 in: Biotechnology Applications for Banana and Plantain Improvement. Inibap, France.

38. Pedreno, M. A., Sabater, F., Munoz, P., and Garcia-Carmona, F. 1987. Effect of different phenols on the NADH-oxidation catalyzed by a peroxidase from lupine. Phytochemistry 12:3133-3136.

39. Pegg, G. F. 1985. Life in a black hole: The micro-environment of the vascular pathogen. Trans. Br. Mycol. Soc. 85:1-20.

40. Ploetz, R. C. 1992. Molecular approaches to identifying Fusarium wilt resistance. Pages 104-115 in: Biotechnology Applications for Banana and Plantain Improvement. Inibap, France.

41. Ride, J. P. 1983. Cell walls and other structural barriers in defense. Pages 215-236 in: Biochemical Plant Pathology. J. A. Callow, ed. Wiley Publishers, Chichester, U.K.

42. Robb, J., Lee, S. W., Mohan, R., and Kolattukudy, P. E. 1991. Chemical characterization of stress induced vascular coating in tomato. Plant Physiol. 97:528-536.

43. Robertson, E. F., Danelly, K., Mallot, P. J., and Reeves, H. C. 1987. Rapid isoelectric focusing in a vertical polyacrylamide minigel system.
Anal. Biochem. 167:290-294.

44. Rowe, P., and Rosales, F. 1992. Diploid breeding at FHIA and the development of Goldfinger (FHIA-01). FHIA Banana and Plantain Breeding Program Annual Report (1992-1993), Honduras.

45. Ryals, J., Uknes, S., and Ward, E. 1994. Systemic acquired resistance. Plant Physiol. 104:1109-1112.

46. Sasaki, M., Yamamoto, Y., and Matsumoto, H. 1996. Lignin deposition induced by aluminum in wheat (Triticum aestivum) roots. Physiol. Plantarum. 96:193-198.

47. Sterjiades, R., Dean, J. F. D., Gamble, G., Himmelsbach, D. S., and Eriksson, K. E. L. 1993. Extracellular laccases and peroxidases from sycamore maple (Acer pseudoplatamus) cell-suspension cultures: Reactions with monolignols and lignin model compounds. Planta 190:75-87.

48. Stover, R. H., and Buddenhagen, I. W. 1986. Banana breeding: Polyploidy, disease resistance, and productivity. Fruits 41:175-191.

49. Torti, S. D., Dearing, M. D., and Kursar, T. A. 1995. Extraction of phenolic compounds from fresh leaves: A comparison of methods. J. Chem. Ecol. 21:117-125.

50. Wyrambik, D., and Grisebach, H. 1975. Purification and properties of isoenzymes of cinnamyl alcohol dehydrogenase from soybean cell suspension cultures. Eur. J. Biochem. 59:9-15. 